\title{
Functional diversity of cover crop mixtures enhances biomass yield and weed suppression in a Mediterranean agroecosystem
}

\author{
M RANALDO*, $\dagger$ (D), S CARLESI* D, A COSTANZO*, $+\&$ P BÀRBERI* \\ *Group of Agroecology, Institute of Life Sciences, Scuola Superiore Sant'Anna, Pisa, Italy, †Isara, AgroSchool for Life, Agroecology and \\ Environment research group, Lyon, France, and $\$$ The Organic Research Centre, Newbury, UK
}

Received 18 December 2018

Revised version accepted 28 July 2019

Subject Editor: Matt Liebman, Iowa State University, Ames, USA

\section{Summary}

Functional diversity of cover crop mixtures is thought to improve biomass production and weed suppression, two key agroecosystem services in organic systems. To test this hypothesis, we selected eight cover crop species belonging to four functional groups: (i) vining growing large-seeded legumes (field pea, common vetch), (ii) erect growing small-seeded legumes (crimson clover, squarrosum clover), (iii) grasses (barley, oats) and (iv) Brassicaceae (radish, black mustard). Nine cover crop mixtures were designed to create a gradient of diversity in terms of number of species and number of functional groups. A control treatment and all monocrops were included in the trial. Regarding cover crop biomass, mixtures outyielded monocrops by an average of $37 \%$. Both functional identity and composition (i.e. trait complementarity) influenced biomass production and weed suppression provided by cover crops. Regression analysis showed that increase in both species diversity and functional diversity in cover crop mixtures improved the provision of agroecosystem services. Results from this study show that complementarity of species functional traits in cover crop mixtures can be used as a strategy to ensure high biomass production and good weed suppression in changing agroecosystems.

Keywords: agrobiodiversity, agroecosystem service, functional trait, resource use complementarity, overyielding, stability, agroecology, organic farming.

Ranaldo M, Carlesi S, Costanzo A \& Bàrberi P (2020). Functional diversity of cover crop mixtures enhances biomass yield and weed suppression in a Mediterranean agroecosystem. Weed Research 60, 96-108.

\section{Introduction}

Cover crops are an essential agronomic tool in sustainable agriculture, especially organic systems. Cover crops can provide many agroecosystem services, for example pest control (Magagnoli et al., 2017), reduction of nitrogen leaching (Hauggaard-Nielsen et al., 2009), carbon and nitrogen fixation (Möller et al., 2008), soil fertility improvement through stimulation of the soil microbial community (Wortman et al.,
2013) and of arbuscular mycorrhizal fungi symbiosis (Njeru et al., 2014) and weed suppression (Bàrberi \& Mazzoncini, 2001; Moonen \& Bàrberi, 2004; Kruidhof et al., 2008).

Biodiversity in agroecosystems (hereafter 'agrobiodiversity') can enhance the provision of agroecosystem services (Altieri, 1999; Malézieux et al., 2009). In particular, functional characteristics of agrobiodiversity elements (genotypes, species and/or habitats) should be analysed to improve agroecosystem functioning

Correspondence: P Bàrberi, Group of Agroecology, Institute of Life Sciences, Scuola Superiore Sant'Anna, Piazza Martiri della Libertà, 33, 
(Moonen \& Bàrberi, 2004; Finn et al., 2013; Costanzo \& Bàrberi, 2016). Increase in cover crop species diversity (i.e. using mixtures instead of monocrops) is a documented example of this approach (Teasdale \& Abdul-Baki, 1998; Wortman et al., 2012; Tosti et al., 2014). Cover crop species may carry different functional traits related to the provision of a given agroecosystem service (Damour et al., 2014; Tribouillois et al., 2015; Wendling et al., 2016). Species bearing traits that are associated with the provision of a given agroecosystem service belong to the same functional group (i.e. a cluster of species providing the same agroecosystem service, following the definition provided by Moonen \& Bàrberi, 2008). Consequently, the level of diversity in a cover crop mixture can be increased not only by augmenting the number of species, but also by increasing the number of functional groups, that is by playing with functional diversity.

Biodiversity can improve agroecosystem functioning, as pointed out in ecological literature (see e.g. Hooper et al., 2005; Petchey \& Gaston, 2006; Díaz et al., 2007). In this study, we refer to previous work by Costanzo and Bàrberi (2014), who proposed different mechanisms by which functional agrobiodiversity in an agroecosystem can affect service provisioning. Agroecosystem functionality can be improved by: (i) functional identity, that is by the presence of a set of homogeneous phenotypic traits related to the expression of given agroecosystem services; (ii) functional composition, that is by the complementary effect of different traits, expressed by co-occurring elements (e.g. species or varieties), on the provision of given agroecosystem services; and (iii) functional diversity sensu stricto, that is the direct effect of heterogeneity within the crop stand on the expression of given agroecosystem services. The relationship between diversity and ecosystem functioning is expected to be one among the three types proposed in literature: (i) linear, where each increase in biodiversity level corresponds to an increase in ecosystem functioning, (ii) logarithmic, when, after an initial increase in ecosystem functioning, the curve reaches a plateau where, over a certain level of biodiversity, there is no increase in ecosystem service provisioning (i.e. each increase in biodiversity would be redundant) or (iii) idiosyncratic, when the expression of the service is species-specific and not related to biodiversity (Bengtsson, 1998).

With this study, we aim to contribute to the growing debate on the effect of species diversity on agroecosystem services provided by cover crops (Schipanski et al., 2014; Finney \& Kaye, 2016). To the best of our knowledge, this is the first study carried out in a Mediterranean environment that tries to analyse ser- vice provisioning in cover crop mixtures that include more than three species.

The aim of our study was to highlight the effect of cover crop diversity on two key agroecosystem services: cover crop biomass production and weed suppression. Each mixture included at least one legume species, to guarantee nitrogen provision. We aimed at having a balanced presence of the other functional groups in the mixtures (grasses and Brassicaceae), as to highlight the potential effect of co-presence of trait complementarity (functional composition effect, as defined above). Mixtures are more complex than monocrops for a farmer to manage; thus, they are required to be more effective than pure stands in providing the desired services. In the case of biomass production, if the proposed mixture is not able to overyield a very productive monocrop, a farmer would not adopt the mixture.

We tested the following specific hypotheses: (i) cover crop mixtures provide a higher total biomass production compared with monocrops; (ii) cover crop mixtures provide higher weed suppression compared with monocrops; (iii) weed presence is negatively correlated to the amount of biomass produced by the cover crop; and finally, we explored the hypothesis that (iv) diversity in terms of number of functional groups is more relevant than diversity in terms of number of species in enhancing target services expression.

\section{Materials and methods}

A field experiment was carried out for two consecutive growing seasons (2015 and 2016) at the Interdepartmental Centre for Agro-Environmental Research (CIRAA) 'Enrico Avanzi' of the University of Pisa, Central Italy (Lat. $43^{\circ} 40^{\prime} \mathrm{N}$; Long. $10^{\circ} 21^{\prime} \mathrm{E}$ ), in organically certified adjacent fields. The soil is a Typic Xerofluvent, characterised by a sandy loam texture (Table 1). Cover crops were broadcast seeded on 27 October 2014 and 26 October 2015 and terminated on 6 May 2015 and 23 May 2016. Plots measured $3 \times 12 \mathrm{~m}$ in 2015 and $4.5 \times 7 \mathrm{~m}$ in 2016 and were arranged upon a randomised complete block design with three replicates. The soil was harrowed prior cover crop seeding, and no fertilisation was applied.

The choice of cover crop species involved in the trial was based on species functional traits for the target services. Following a preliminary screening trial performed in a growth chamber (Ranaldo et al., 2015), we identified eight candidate species belonging to four functional groups: (i) large-seeded legumes (LSL), characterised by a major development in height and climbing habit, with roots spreading outwards from 
Table 1 Summary of soil characteristics from the experimental fields. $T^{\circ}$ max and $T^{\circ}$ min refer to average maximum and minimum daily temperatures

\begin{tabular}{llllllllllr}
\hline Year & $\mathrm{pH}$ & $\begin{array}{l}\mathrm{N} \text { tot } \\
\%\end{array}$ & $\begin{array}{l}\text { SOM } \\
\%\end{array}$ & $\begin{array}{l}\mathrm{P} \text { (Olsen) } \\
\mathrm{ppm}\end{array}$ & $\begin{array}{l}\text { Clay } \\
\%\end{array}$ & $\begin{array}{l}\text { Loam } \\
\%\end{array}$ & $\begin{array}{l}\text { Sand } \\
\%\end{array}$ & $\begin{array}{l}T^{\circ} \max \\
{ }^{\circ} \mathrm{C}\end{array}$ & $\begin{array}{l}T^{\circ} \text { min } \\
{ }^{\circ} \mathrm{C}\end{array}$ & $\begin{array}{l}\text { Rainfall } \\
\mathrm{mm}^{2}\end{array}$ \\
\hline 2015 & 7.79 & 2.76 & 3.47 & 4.60 & 21.07 & 21.50 & 57.43 & 21.17 & 9.94 & 1081.80 \\
2016 & 6.72 & 1.64 & 2.53 & 6.33 & 18.86 & 18.09 & 63.06 & 20.51 & 10.00 & 1088.40 \\
\hline
\end{tabular}

the main taproot (field pea, Pisum sativum L., and common vetch, Vicia sativa L.); (ii) small-seeded legumes (SSL), able to cover the soil quickly, developing a deep, branched taproot (crimson clover, Trifolium incarnatum L., and squarrosum clover Trifolium squarrosum L.); (iii) highly competitive grasses, characterised by fascicled root system (POA: barley, Hordeum vulgare L., and oats, Avena sativa L.); and (iv) taprooted Brassicaceae in which residues have an allelopathic effect (Couëdel et al., 2018; Sturm et al., 2018), (BRS: radish, Raphanus sativus L., and black mustard, Brassica nigra L.). Cover crop cultivar choice was also based on performances recorded in the preliminary screening trial. Plant biomass, height and root length were recorded.

All monocultures and a control treatment with no cover crop were included in the field trial. Mixtures were designed with the aim of creating a gradient of diversity in terms of number of species and number of functional groups. We designed four-two-species mixtures, four-four-species mixtures and one-eight-species mixture (Table 2). Based on the homogeneity of functional traits within functional groups, more relevance has been given to the presence of a particular functional group compared with the presence of a particular species in mixtures. A main constraint for the design of mixtures was that nitrogen provision to the agroecosystem by cover crops was a required service by the farmer. Therefore, mixtures always comprised at least one legume species. Mixtures were composed adding to LSL and/or SSL one, two or three species belonging to another functional group.

Sowing densities of monocultures were based on recommended seed density by seed producers. To constitute the mixtures, we used a partial replacement approach, reducing the recommended sowing rate of each species to $50 \%$ in two-species mixtures, to $25 \%$ in four-species mixtures and to $12.5 \%$ in eight-species mixture as compared to monocrops (Table 2). Actual sowing rates were adjusted according to the results of a germination trial performed before sowing both in 2015 and 2016. The high dose recorded in 2016 for black mustard is due to a dramatic decline in seed germinability from 2015 to 2016.

During cover crop development, crop and weed density was recorded before and after the winter period in both years (data not shown). Cover crop biomass was assessed just before cover crop termination. Plant above ground biomass was sampled in three $0.5 \times 0.5 \mathrm{~m}$ quadrats plot $^{-1}$ and separated into cover crop species and total weed biomass. As 'weed', we intend all nonplanted vegetation grown in the plot. Samples were oven dried at $60^{\circ} \mathrm{C}$ until constant weight. Cover crop termination was carried out on 6 May 2015 and 23 May 2016 with a roller crimper followed by flame weeding to minimise re-growth (Frasconi et al., 2016).

The second year was characterised by problematic soil conditions. The soil showed a hardpan layer and was subjected to water-logging, particularly in autumn. Among the 2 years, we observed different soil physical conditions and different rainfall pattern in autumn (Fig. 1). In view of this situation, the data from the 2 years could be interpreted as data from two different environments.

In all analyses, species composition of treatments was considered as 'intended' composition, not as actual composition at the time of sampling. This means that the composition of treatments we considered is the result of the interactions between seeded species and the environment (weather, soil and wild vegetation). Using this approach, we were able to test performances of cover crop mixtures and challenge their effectiveness in real and also exceptional on-farm conditions.

\section{Analysis}

The interaction between the variable 'year' and the explanatory variables was significant for all performed analyses; consequently, data were analysed separately by year.

Total biomass (cover crop + weeds) and weed biomass were analysed using a linear model. Interaction between the variable 'treatment' and the variable 'block' was taken into account. We used a Tukey HSD post hoc test to separate means $(P<0.05)$. First-year data of weed biomass were log-transformed $\left[x^{\prime}=\log \right.$ $(x+0.5)]$ to meet normality and homoscedasticity assumptions.

Total biomass was analysed to determine overyielding (i.e. when biomass in mixture is higher than mean biomass in monocrops) and transgressive overyielding (i.e. when mixture produces higher biomass than the 


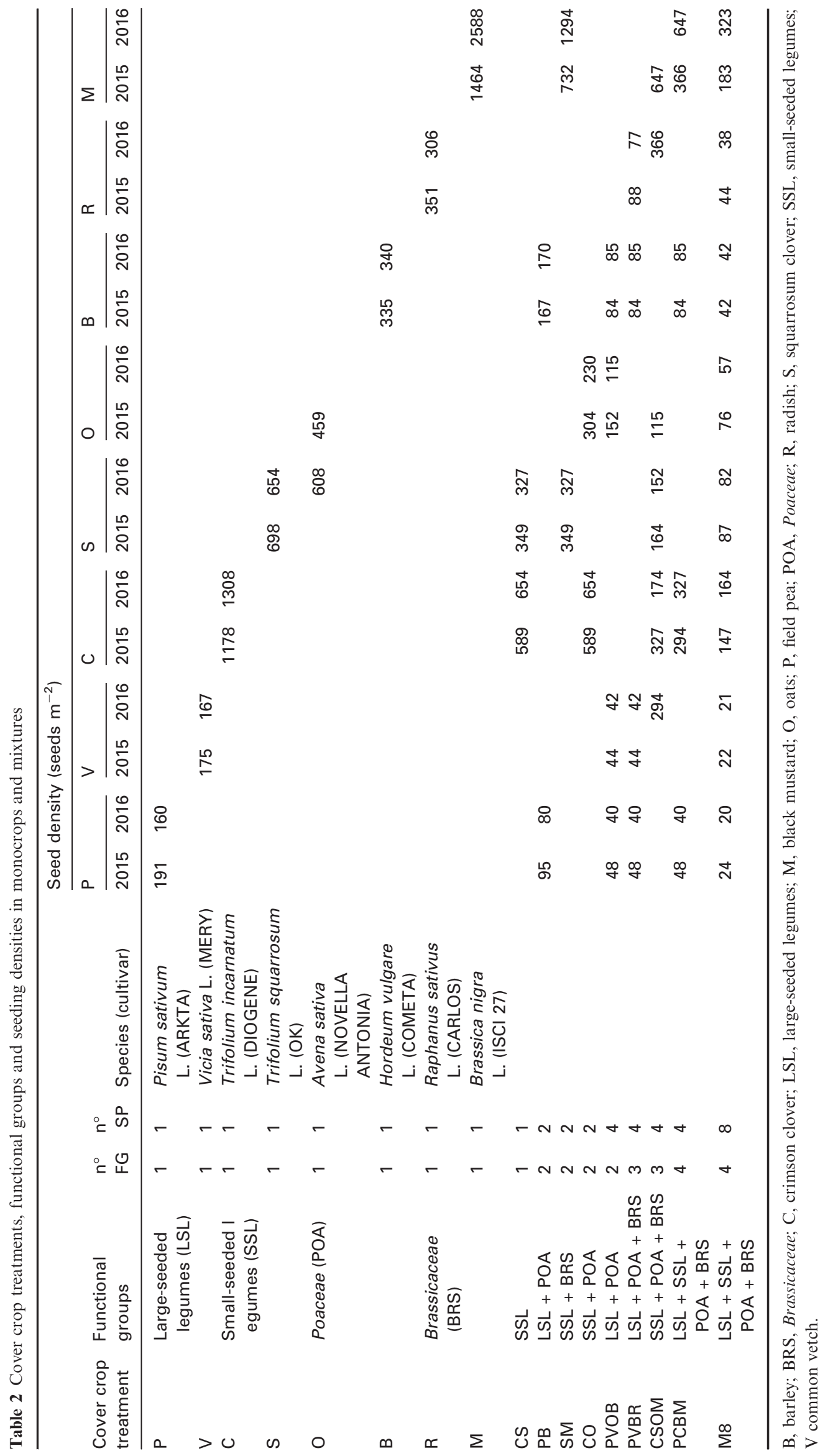




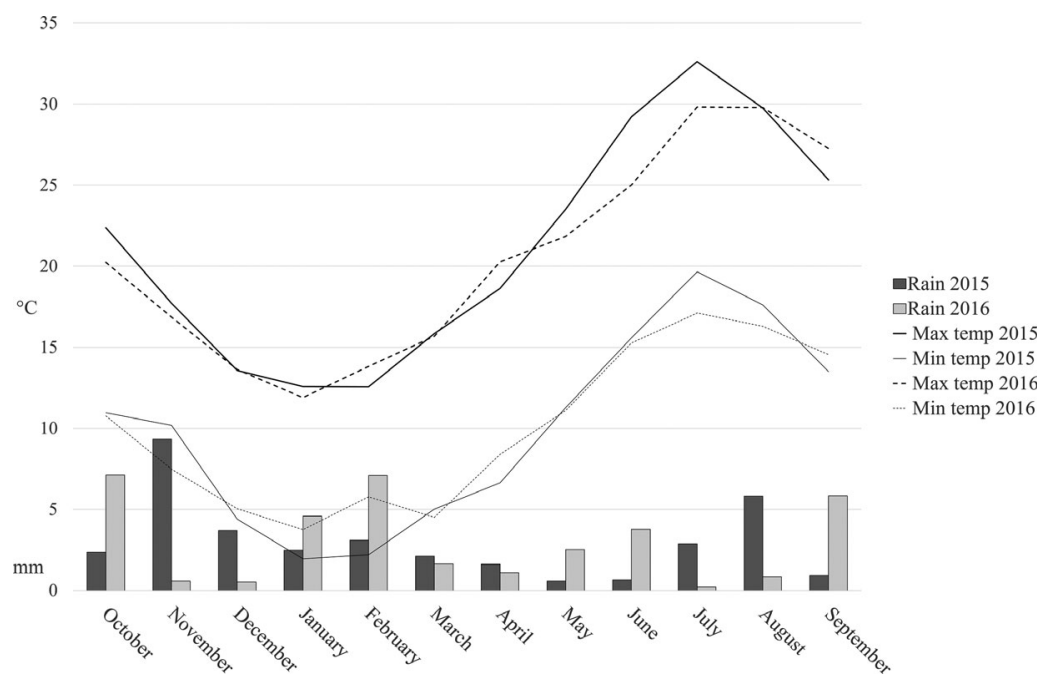

Fig. 1 Average daily max and min temperature $\left({ }^{\circ} \mathrm{C}\right)$ and average daily rainfall $(\mathrm{mm})$ at San Pero a Grado, Pisa, Italy (Lat. $43^{\circ} 40^{\prime} \mathrm{N}$; Long. $10^{\circ} 21^{\prime} \mathrm{E}$ ) in 2015 and 2016 (respectively the first and second experiment year). most productive monospecific stand). Overyielding was determined using a linear model, contrasting productivity of all monocultures against the mixture comprising all of them (M8). Transgressive overyielding was determined with the method proposed by Schmid et al. (2008):

$$
\mathrm{NE}_{\text {trans }}>\mathrm{ND}\left(1-\frac{1}{N}\right) \mathrm{Ss}
$$

where $\mathrm{NE}_{\text {trans }}$ is the difference between the simulated biomass of the highest productive species and the average species in monoculture, ND is the standard normal deviate for probability $P=1-1 / N, N$ is the number of species, and Ss is the pooled between species and within species standard deviation. Please refer to Schmid et al. (2008) for further details. The maximum attainable productivity of monocultures was simulated using the model that takes into account mean values and variability (measured as standard deviation) between monocultures and within monoculture treatments replicates. The mean of the simulated monoculture maxima is then compared with the mean of mixture biomass production.

We performed a regression analysis to test the effect of cover crop biomass on total weed biomass (2015 data are log-transformed). Partial regressions for each cover crop treatment were also performed.

Analysing the relationship between agroecosystem services and diversity, we considered two aspects of diversity: diversity per se (i.e. the number of species included in a mixture) and functional diversity (i.e. the number of functional groups involved in a mixture). We used mixed effect models to determine the relationship between biomass production and diversity of species and functional groups in the mixtures, using block as a random effect. As a measure of the explained variance in mixed effect models, we used marginal $R^{2}$ (Mar. $R^{2}$ ) and conditional $R^{2}$ (Con. $R^{2}$ ). Mar. $R^{2}$ refers to the variance explained by the fixed effect of the model, and Con. $R^{2}$ refers to the variance explained by both fixed and random effects (Nakagawa \& Schielzeth, 2013). Model selection was performed using the likelihood ratio test (Zuur et al., 2009). The same statistical tools were used to analyse the effect of cover crop species and functional diversity on total weed biomass (data log-transformed), and the weed suppression service provided by cover crop mixtures.

We evaluated the weed control service provision $\left(S_{\mathrm{w}}\right)$ with a simple index previously used by Finney et al. (2016):

$$
S_{\mathrm{w}}=W_{\mathrm{c}}-W_{\mathrm{t}}
$$

where $S_{\mathrm{w}}$ is the amount of weed biomass suppressed $\left(\mathrm{g} \mathrm{m}^{-2}\right), W_{\mathrm{c}}$ is the weed biomass in the control, and $W_{\mathrm{t}}$ is the weed biomass in the specific treatment. The higher the value of $S_{\mathrm{w}}$, the higher the provision of the weed suppression service. If the value is negative, the cover crop treatment provides a disservice. Mixed effect models were used to determine the effect of treatments on $S_{\mathrm{w}}$. Dunnett's test was used as test for multiple comparisons of the means.

All analyses were carried out on R ( $\mathrm{R}$ Core Team 2017) in RStudio (RStudio Team 2016) using agricolae (DeMendiburu, 2016) and multcomp packages (Hothorn et al., 2008) for post hoc analysis; lme4 (Bates et al., 2014) and MuMIn (Barton, 2016) packages for mixed modelling; and ggplot2 package (Wickham, 2009) for graphic representations.

\section{Results}

\section{Total biomass}

Treatment effect on total biomass (cover crop + weeds) was significant in both years $\left(r^{2}=0.71, P<0.001\right.$ in 2015 and $r^{2}=0.62, P<0.001$ in 2016). In all mixtures, 
total biomass in 2015 was significantly higher than the control. The same was not true for monocrops (Fig. 2). Values of total biomass for all the mixtures were significantly higher compared with the two BRS and LSL monocrops, with the exception of PVOB. The most productive treatments were SSL (squarrosum clover, $750.5 \pm 108.12 \mathrm{~g} \mathrm{~m}^{-2}$; crimson clover, $737.1 \pm 87.31$ $\left.\mathrm{g} \mathrm{m}^{-2}\right)$, CS $\left(807.4 \pm 114.01 \mathrm{~g} \mathrm{~m}^{-2}\right)$, CSOM $(745.3 \pm$ $\left.106.56 \mathrm{~g} \mathrm{~m}^{-2}\right)$ and PCBM $\left(734.1 \pm 136.99 \mathrm{~g} \mathrm{~m}^{-2}\right)$. Regarding the functional groups tested in the trial, in the first year M8 did not differ from PCBM, suggesting that species in M8 were redundant and did not improve mixture functionality.

In the second year, only M8, PVBR and PVOB treatments recorded significantly higher total biomass than the control (respectively $595.8 \pm 106.85$, $572.5 \pm 118.13,537.8 \pm 197.90 \mathrm{~g} \mathrm{~m}^{-2}$ ) and were more productive than all single species treatments apart from common vetch, all two-species mixtures apart from SM (only M8 and PVBR were more productive) (Fig. 2). The mixtures M8 and PVBR were also significantly more productive than the four-species mixtures CSOM and M8 was more productive than PCBM. Higher biomass production of SSL compared with the other functional groups was not confirmed; instead, LSL seemed to be favoured by environmental conditions in 2016.

Overyielding was not observed in the first year, while total biomass of M8 in 2016 was significantly greater than the average of its component species as monocrops $\left(r^{2}=0.51, \quad P<0.001\right) . \quad$ Transgressive overyielding was not achieved.

\section{Weed biomass}

The most abundant weeds at the time of cover crop termination were Senecio vulgaris L., Helmintotheca echioides L. and Alopecurus myosuroides L. (respectively 14,11 and 8.9 plants $\mathrm{m}^{-2}$ ) in 2015; and Ranunculus repens L., Juncus tenageja Ehrh. and Lolium multiflorum Lam. (respectively 54.6, 31.3 and 23.3 plants $\mathrm{m}^{-2}$ ) in 2016.

Only the weed biomass found in LSL monocrops and in black mustard did not differ from the control in 2015 (Fig. 2). In the first year, M8, PCBM, PB and $\mathrm{CO}$ had a significantly lower biomass than the largeseeded legume monocrops while PB and PCBM also had a lower weed biomass than the crucifer monocrops

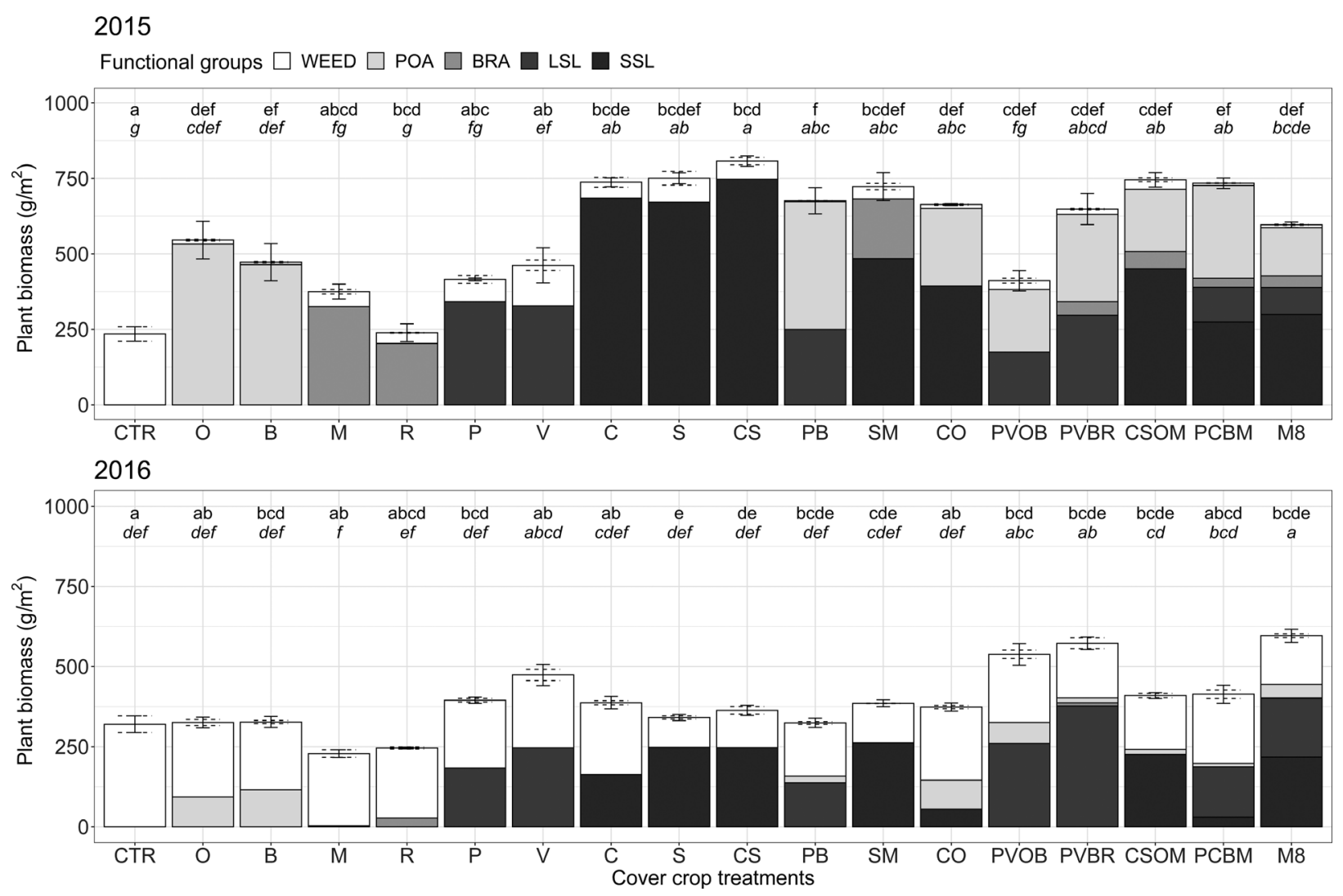

Fig. 2 Total biomass in the first and second year (top and bottom graph respectively). Shades of grey indicate cover crop biomass in mixtures partitioned by functional group. In white weed biomass, different letters indicate treatment differences in weed biomass (upper row of letters) and total biomass (cover crops + weeds; lower, italicised row of letters) at $P<0.001$, whereas shared letters indicate no treatment effects at $P<0.05$. Data are means \pm SEM. Treatment codes are explained in Table 2; CTR, control. 
and the small-seeded legume mixture. In grass monocultures, weed abundance was low and comparable to that of mixtures. The treatment with the lowest amount of weed biomass was PB $\left(3.9 \pm 0.87 \mathrm{~g} \mathrm{~m}^{-2}\right)$. The association of a legume with a non-legume in $\mathrm{PB}$ increased the weed suppressive ability compared with the field pea monocrop (-93\%) but not compared with the barley monocrop. A similar pattern was observed in $\mathrm{CO}$, where total weed biomass was $12.3 \pm 8.90 \mathrm{~g} \mathrm{~m}^{-2}, 54 \%$ lower than in the crimson clover monocrop and not significantly different from the oats monocrop. The same positive effect was not recorded when a legume was mixed with a crucifer. Weed biomass did not differ between SSL treatments.

In the second year, weed biomass was lower than the control in treatments including squarrosum clover (S, CS and SM; in the latter, black mustard biomass was negligible: $0.3 \pm 0.87 \mathrm{~g} \mathrm{~m}^{-2}$ ). For LSL, weed biomass was significantly lower than the control for pea monocrop, PB, PVOB and PVBR. In M8, weed biomass $\left(151.5 \pm 23.87 \mathrm{~g} \mathrm{~m}^{-2}\right)$ did not differ from the most effective treatment (squarrosum clover: $\left.92.8 \pm 20.99 \mathrm{~g} \mathrm{~m}^{-2}\right)$.

\section{Weed suppression service}

Cover crops always provided weed suppression service $\left(S_{\mathrm{w}}\right)$, but the picture was different among the two environments. In the first year, $S_{\mathrm{w}}$ was significantly higher than the control for all the treatments $(P<0.001$, except for vetch $P<0.01)$. In the second year, $S_{\mathrm{w}}$ was higher in cover crop treatments compared with the control, but performances were different among treatments (Fig. 3). In 2016 monocrops, weed suppression was generally lower compared with mixtures. Weed biomass reduction compared with the control ranged from $227 \pm 104.71 \mathrm{~g} \mathrm{~m}^{-2}$ for squarrosum clover to $86.8 \pm 148.16 \mathrm{~g} \mathrm{~m}^{-2}$ for oats. We observed a high
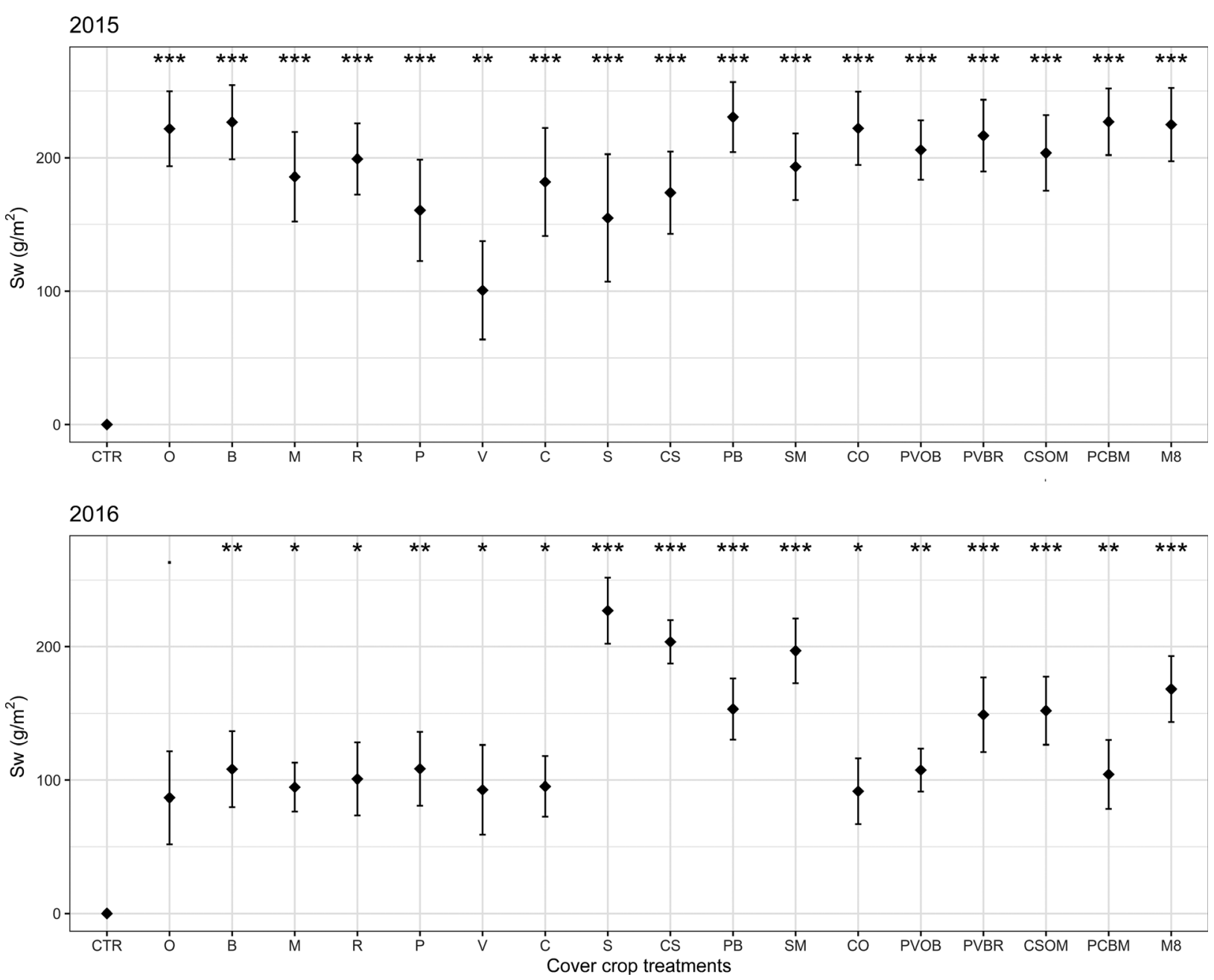

Fig. 3 Weed suppression services $\left(S_{\mathrm{w}}\right)$ of cover crop mixtures expressed as weed biomass reduction compared with the control $\left(\mathrm{g} \mathrm{m}^{-2}\right)$. Diamonds represent means, and bars represent the standard error of cover crop treatments. $* * * P<0.001 ;{ }^{* *} P<0.01 ; * P<0.05$; and $. P<0.1$. Treatment codes are explained in Table 2; CTR, control. 
variability in the magnitude of service provisioning among treatments.

\section{Relationship between cover crop and weed biomass}

Cover crop biomass showed a negative correlation with weed biomass in both years (Fig. 4). Weed-cover crop biomass relationship was significantly different among treatments only in 2015 (Table 3). A very strong negative relationship was found for squarrosum clover monocrop $\left(\mathrm{S}, r^{2}=0.29, P<0.01\right)$, while a weak negative relationship was found for PVOB $\left(r^{2}=0.45\right.$, $P<0.05)$ and $\operatorname{CSOM}\left(r^{2}=0.32, P<0.05\right)$.

\section{Effect of diversity on cover crop and weed biomass}

We found a significant relationship between cover crop biomass and species diversity or number of functional groups in both years (Fig. 5).

Increasing both the number of species and functional groups in the mixtures decreased total weed biomass in 2015. Our results indicate that the increase in functional groups was more effective than the increase in species number in reducing total weed biomass, as suggested by the higher level of variance explained (Mar $R^{2}=0.07$ for species diversity vs. Mar $R^{2}=0.10$ for functional diversity, Fig. 6). No trend was detected in the second year.

\section{Discussion}

Our first hypothesis was that productivity in mixture treatments would be higher compared with monocrop treatments. We observed an advantage of mixtures in productivity over monospecific stands, as found in other studies (Smith et al., 2014; Finney et al., 2016). In the tested treatments, all different mechanisms related to service provisioning by functional biodiversity played a role in enhancing cover crop biomass production service. In favourable field conditions, functional identity (homogeneity of traits enhancing services provisioning) enhanced biomass production, particularly in the case of clovers, which were the most productive species. Their functional identity was

\section{5}

Fig. 4 Regression of total weed biomass on cover crop biomass in 2015 and 2016. Points represent weed biomass observations.

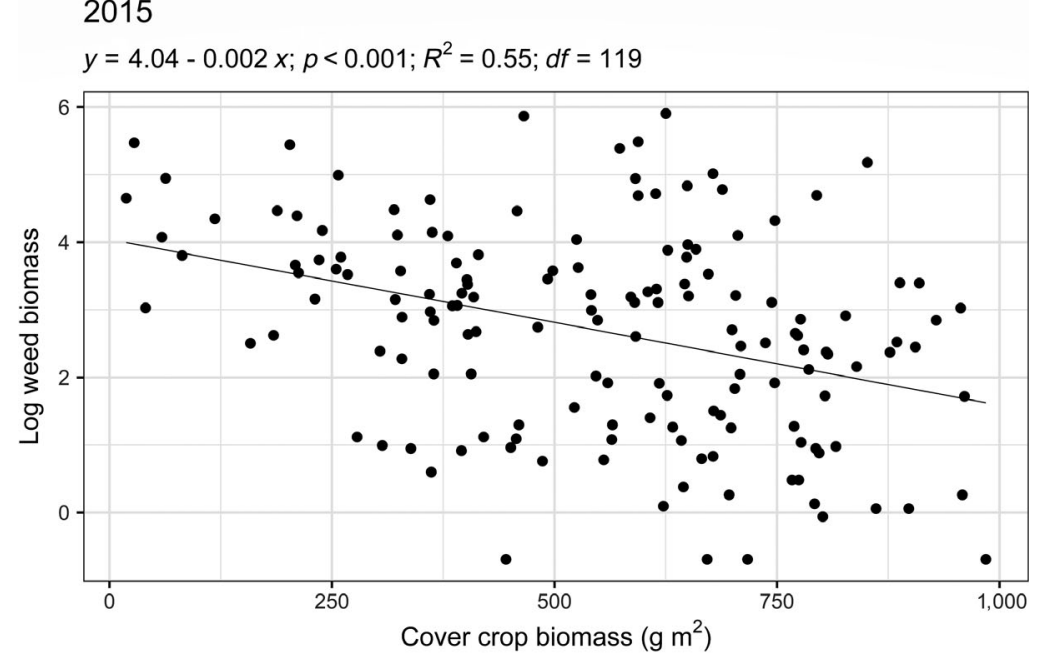

2016

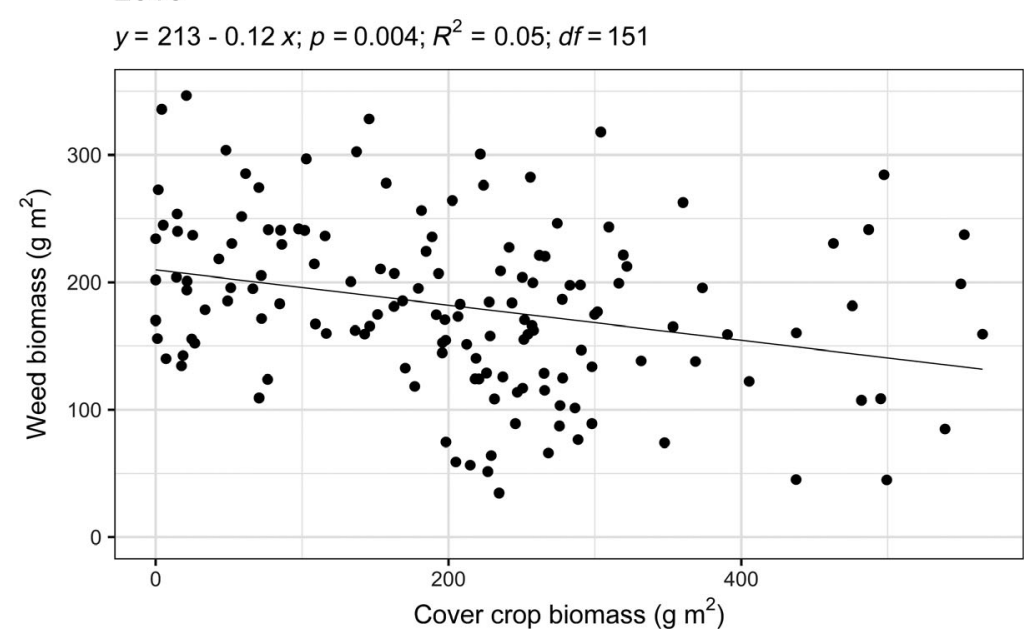


Table 3 Intercept and slope estimates for weed vs. cover crop biomass partial regression model for the 2015 data (weed biomass $\sim$ cover crop biomass * cover crop treatment). Standard error of the mean, $t$-values and significance values are also presented. For treatment code, refer to Table 2

\begin{tabular}{|c|c|c|c|c|c|c|c|c|}
\hline Treatment & Intercept & SE & $t$ value & $\operatorname{Pr}(>|t|)$ & Slope & SE & $t$ value & $\operatorname{Pr}(>|t|)$ \\
\hline $\mathrm{O}$ & 2.564 & 0.978 & 2.622 & 0.010 & -0.001 & 0.002 & -0.570 & 0.570 \\
\hline B & 3.412 & 1.276 & 0.665 & 0.508 & -0.005 & 0.002 & -1.525 & 0.130 \\
\hline$M$ & 3.677 & 1.452 & 0.767 & 0.445 & 0.000 & 0.004 & 0.218 & 0.828 \\
\hline $\mathrm{R}$ & 3.519 & 1.238 & 0.772 & 0.442 & 0.000 & 0.004 & 0.242 & 0.809 \\
\hline$P$ & 6.738 & 1.993 & 2.094 & 0.038 & -0.008 & 0.005 & -1.358 & 0.177 \\
\hline V & 4.875 & 1.189 & 1.944 & 0.054 & -0.001 & 0.002 & 0.096 & 0.924 \\
\hline C & 7.419 & 3.483 & 1.394 & 0.166 & -0.006 & 0.005 & -1.063 & 0.290 \\
\hline $\mathrm{S}$ & 14.883 & 4.222 & 2.918 & 0.004 & -0.018 & 0.006 & -2.675 & 0.009 \\
\hline CS & 7.156 & 2.251 & 2.040 & 0.044 & -0.005 & 0.003 & -1.237 & 0.219 \\
\hline PB & 2.624 & 1.804 & 0.033 & 0.974 & -0.002 & 0.003 & -0.419 & 0.676 \\
\hline SM & -0.256 & 1.886 & -1.495 & 0.137 & 0.005 & 0.003 & 2.003 & 0.047 \\
\hline $\mathrm{CO}$ & 2.679 & 2.424 & 0.047 & 0.962 & -0.001 & 0.004 & -0.040 & 0.968 \\
\hline PVOB & 5.062 & 1.391 & 1.796 & 0.075 & -0.007 & 0.003 & -1.942 & 0.054 \\
\hline PVBR & 4.421 & 1.521 & 1.221 & 0.224 & -0.003 & 0.002 & -0.790 & 0.431 \\
\hline CSOM & 8.936 & 2.833 & 2.249 & 0.026 & -0.009 & 0.004 & -1.971 & 0.051 \\
\hline РСВM & -1.270 & 2.457 & -1.561 & 0.121 & 0.004 & 0.003 & 1.401 & 0.164 \\
\hline M8 & 1.601 & 2.380 & -0.405 & 0.687 & 0.000 & 0.004 & 0.352 & 0.725 \\
\hline
\end{tabular}

expressed in monocrops and in the CS mixture. At the same time, functional composition (complementarity of traits) also provided a higher expression of the service in mixtures compared with monocrops. In particular, mixing large-seeded legumes or mustards with other species belonging to one, two or three different functional groups led to a higher biomass production compared with the monocrops. The picture changed when the same treatments performed in a challenging environment. Here, the highest service provision (i.e. biomass production) was associated with the highest level of diversity, represented by the eight-species mixture. This gives a strong indication of the importance of cover crop diversity under difficult field conditions. While functional identity and composition played a major role in normal environmental conditions, diversity and redundancy of functional traits (functional diversity sensu strictu) were keys to ensure sufficient biomass production in a challenging agroecosystem, as in 2016.

The highest diversity mixture (M8) overyielded its component species in 2016, confirming the importance of functional diversity when field conditions are difficult or unpredictable. Transgressive overyielding was not observed, as it often happens also in ecological research (Cardinale et al., 2011).

Weed presence was generally higher in 2016 compared with 2015. Particular weed species presence provided some indication about the difference in environmental conditions in the 2 years. R. repens $\mathrm{L}$. and $J$. tenageja Ehrh. were the most abundant species in 2016 field, and they are typical of humid environments and disturbed soils that are frequently water-logged.
Looking at weed biomass reduction, in 2015 functional identity of grasses, and not the most productive clovers, proved to provide good service expression. Functional composition too enhanced weed suppressive ability in mixtures. This was particularly the case for the pea and barley mixture (PB) and the crimson clover and oat mixture (CO). Although grass cover crops were more suppressive than legume monocrops, as also found by Ramirez-Garcia et al. (2015), weed biomass reduction in legume-grass mixtures was comparable to that in competitive grass monocrops. A similar effect in legume-grass binary mixtures was found by Hauggaard-Nielsen et al. (2001) and Corre-Hellou et al. (2011). The advantage of such mixtures is that biologically fixed nitrogen is added into the system and that the cover crop biomass has a more balanced $\mathrm{C} / \mathrm{N}$ ratio (Kuo \& Sainju, 1998; Korsaeth et al., 2002).

Complementarity of resource use may be a major mechanism explaining the effect of diversity on weed suppression. Smith et al. (2010) suggested that when the soil resource pool is more diversified, weed abundance is expected to be lower, and termed this effect the Resource Pool Diversity Hypothesis. In our case, we can hypothesise that a similar effect might have occurred, fostered by the diversification in cover crop functional traits. In other words, better weed suppression can be achieved through the synergy between complementary species traits in a cover crop mixture, that is through a functional composition effect (Costanzo \& Bàrberi, 2014). Complementary traits may involve the different habits, $\mathrm{N}$ acquisition strategy and root system development of the species considered in this trial. 

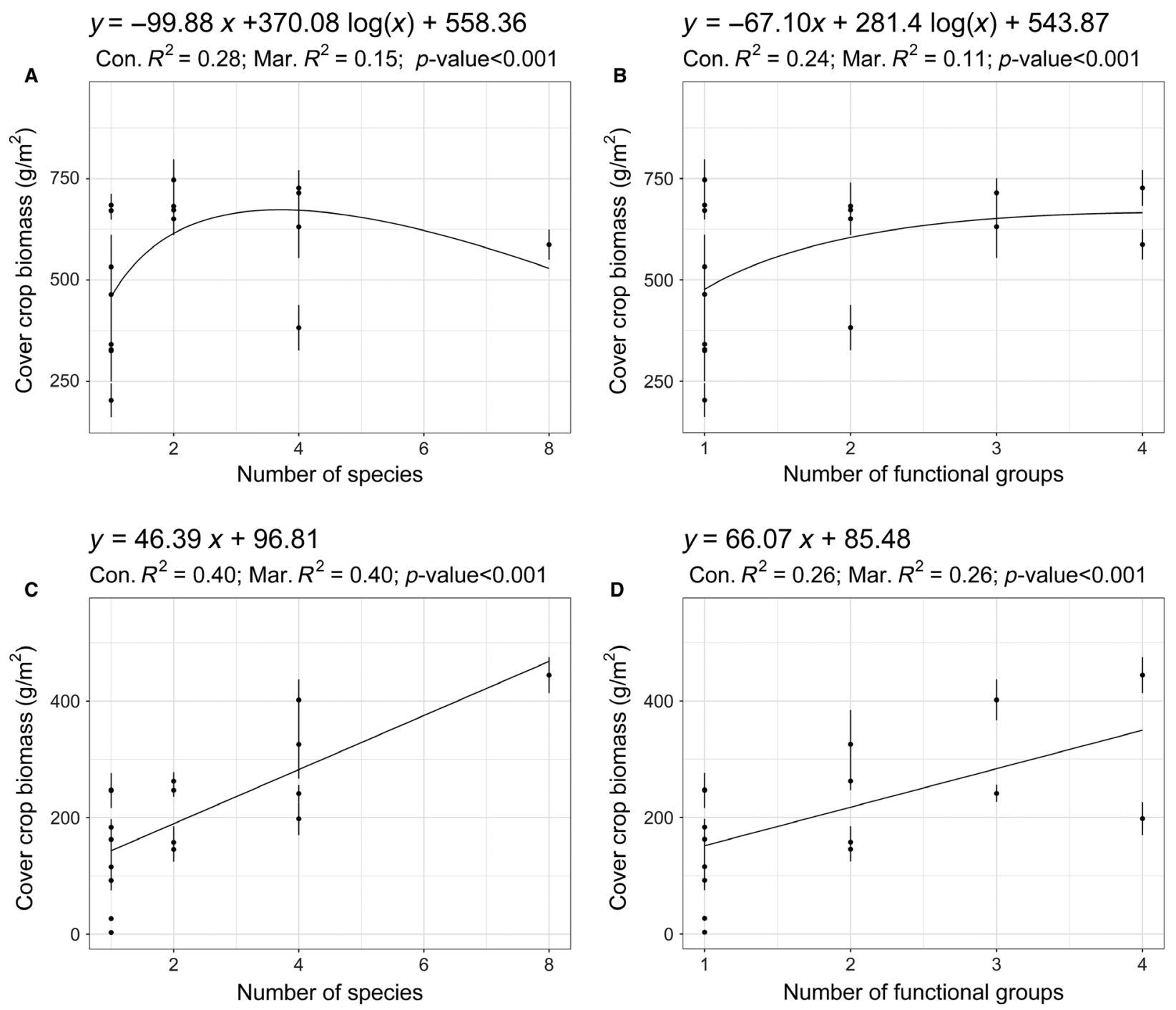

Fig. 5 Effect of species number and functional group number on cover crop biomass in 2015 (A and B) and 2016 (C and D). Points represent the mean, and bars represent SEM of each cover crop treatment. Points of treatments at level 1 of both species and functional diversity overlap in 2016. Conditional and marginal $R^{2}$ are reported.

Functional identity of squarrosum clover, likely due to its mat-like prostrate growth during early developmental stages, was key to achieve a high weed suppression service $\left(S_{\mathrm{w}}\right)$, which was also stable across the 2 years. However, functional complementarity and diversity expressed by mixtures (i.e. PB, PVBR, CSOM) and particularly the eight-species mixture proved to be equally important, especially when weed infestation was high.

We found an overall negative correlation between cover crop biomass productivity and weed biomass, although a clear pattern among treatments was found only in one case, in 2015. If weed biomass reduction for squarrosum clover monocrop was strongly related to its high productivity, such conclusion cannot be drawn for the other treatments. Generally, biomass productivity alone may not be the most important functional trait affecting weed suppression; in fact, in high functional diversity systems, multiple functional traits (i.e. nutrient use strategy, growth form, root system) can be responsible of a target service (as highlighted by Díaz et al., 2007).

Exploring the effect of species and functional diversity on services provisioning, our data suggest that increase in both species diversity and functional diversity can lead to higher biomass production in cover crop mixtures compared with monospecific stands. However, the effect of the two types of diversity changed with the environment. In 2015, only functional diversity had a significant effect on biomass, while in 2016 the effect was stronger for species diversity. This can be interpreted in the light of the discussion by Bengtsson (1998) on the relationships between biodiversity and ecosystem functioning. In 2015, the 


$$
y=0.11 x-0.90 \log (x)+2.92
$$
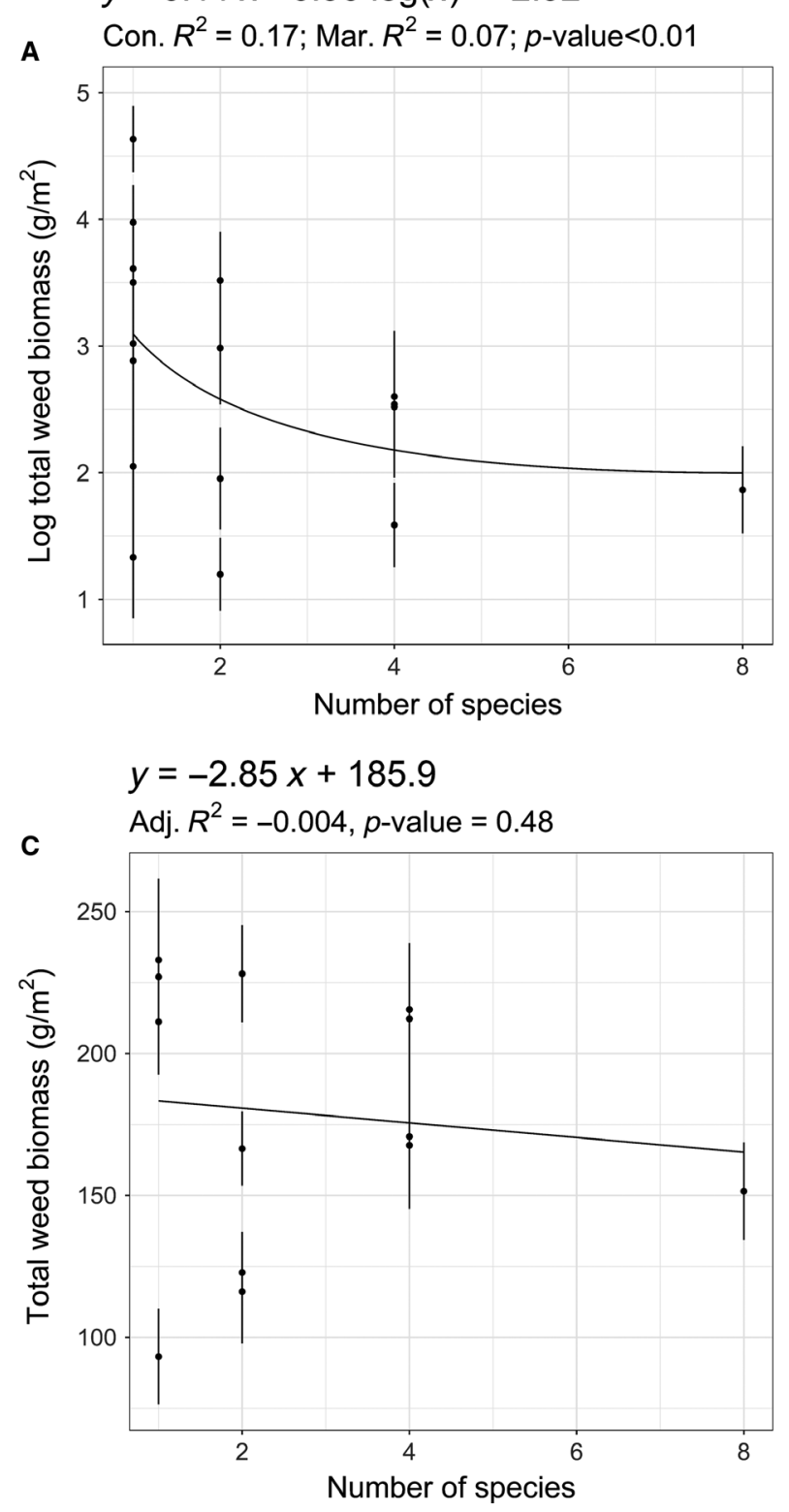

$$
y=0.37 x-1.6 \log (x)+2.78
$$

B $\quad$ Con. $R^{2}=0.21 ;$ Mar. $R^{2}=0.10 ; p$-value $<0.001$

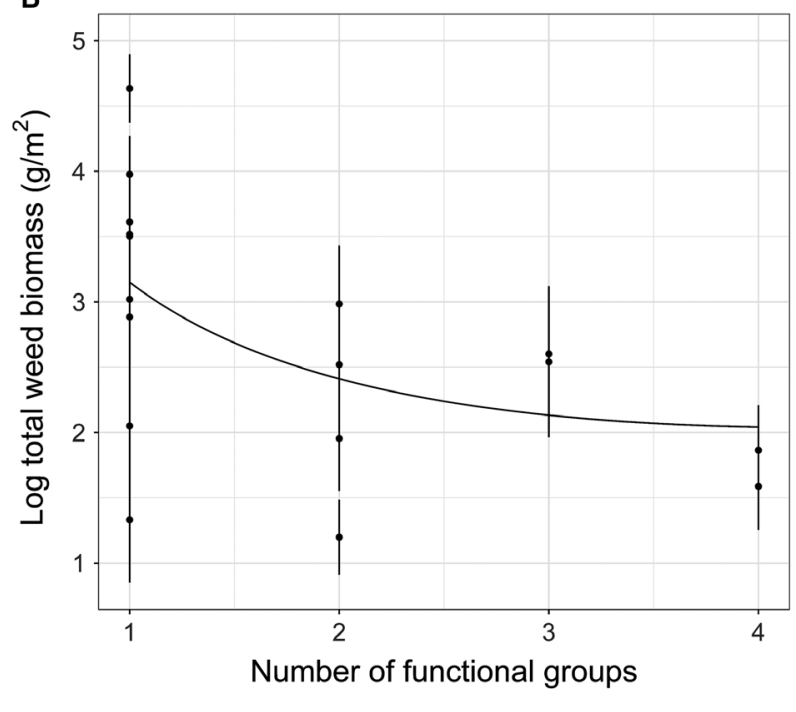

$y=0.24 x+178.37$

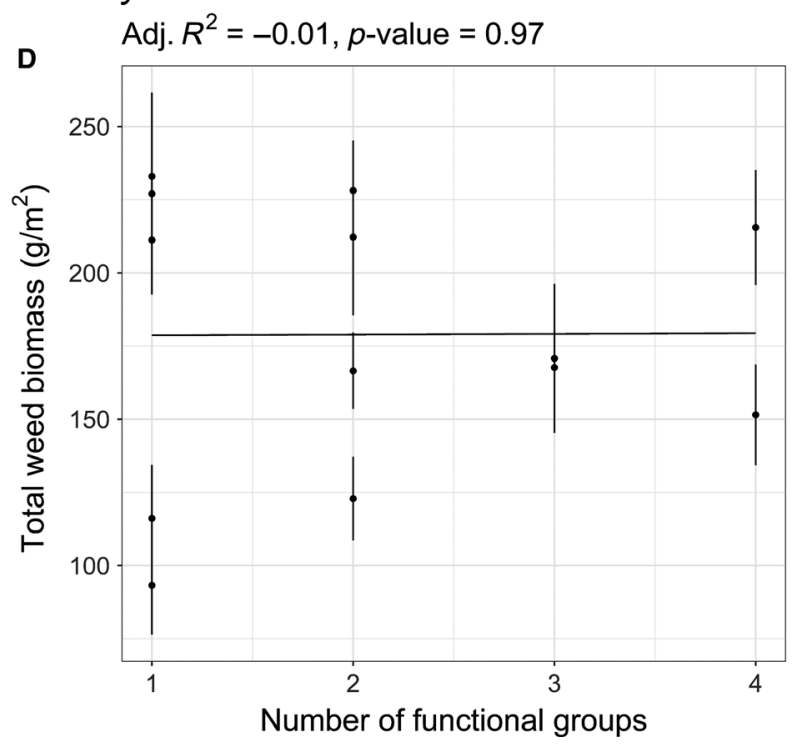

Fig. 6 Effect of species number (A) and functional group number (B) on total weed biomass in 2015 (A and B) and 2016 (C and D). Points represent the mean, and bars represent SEM of each cover crop treatment. Conditional and marginal $R^{2}$ are reported.

ecosystem function-diversity relationship followed a logarithmic function, suggesting the expression of the redundancy hypothesis (i.e. after a certain level, increasing biodiversity does not result in an increase in the ecosystem function; in other words, any added element is redundant). In the second year, the relationship was linear and stronger for species diversity, indicating that each increase in species diversity led to a better ecosystem functioning. Our results suggest that in unfavourable environments, species are less likely to be redundant; on the contrary, diversity can sustain biomass productivity. The redundancy-type relationship was also found for weed biomass in 2015. This suggests that in favourable environments, diversity can increase agroecosystem services provision only up to a certain level. No significant relationship between total weed biomass and treatments' diversity was found in 2016 probably due to the very high weed pressure.

Analysing the effect of specific combinations of cover crop species and functional groups, we found that all components of functional biodiversity can support agroecosystem service provisioning, but which kind of diversity is more effective depends on the environment, farmer's objectives and, not least, temporal scale. In the short term and under predictable pedoclimatic conditions, provided that farmers are able to 
choose the best cover crop for their fields, exploiting the functional identity of the cover crop can be a way to achieve specific agroecosystem services such as weed suppression and biomass production. However, to ensure service provision in a changing environment, the use of cover crop functional composition and diversity may be a better (and safer) option.

\section{Acknowledgements}

This research was carried out within the frame of FERTILCROP project (http://www.fertilcrop.net/) funded via the ERA-net CORE Organic Plus (http:// www.coreorganic.org). We would like to thank the Interdepartmental Centre for Agro-Environmental Research (CIRAA) 'Enrico Avanzi' of the University of Pisa for hosting the field trial and for the precious help during field operations. We would also like to thank Dr. Christian Frasconi and Dr. Daniele Antichi for their help and advice. Finally, thanks to Dr. Cian Blaix for his help during manuscript revision.

\section{References}

Altieri MA (1999) The ecological role of biodiversity in agroecosystems. Agriculture, Ecosystems and Environment 74, 19-31.

BÀrberi P \& MAZzoncini M (2001) Changes in weed community composition as influenced by cover crop and management system in continuous corn. Weed Science 49, 491-499.

Barton K (2016) MuMIn: Multi-Model Inference. R package version 1.15.6. Available at: https://CRAN.Rproject.org $/$ package $=$ MuMIn (Last accessed 7 January 2016).

Bates D, Mächler M, Bolker B \& Walker S (2014) Fitting linear mixed-effects models using lme4. Journal of Statistical Software 67, 51.

BENGTSSON J (1998) Which species? What kind of diversity? Which ecosystem function? Some problems in studies of relations between biodiversity and ecosystem function. Applied Soil Ecology 10, 191-199.

Cardinale BJ, Matulich KL, Hooper DU et al. (2011) The functional role of producer diversity in ecosystems. American Journal of Botany 98, 572-592.

Corre-Hellou G, Dibet a, Hauggaard-Nielsen H et al. (2011) The competitive ability of pea-barley intercrops against weeds and the interactions with crop productivity and soil $\mathrm{N}$ availability. Field Crops Research 122, 264-272.

Costanzo A \& BÀrberi P (2014) Functional agrobiodiversity and agroecosystem services in sustainable wheat production. A review. Agronomy for Sustainable Development 34, 327-348.

Costanzo A \& BÀrberi P (2016) Field scale functional agrobiodiversity in organic wheat: effects on weed reduction, disease susceptibility and yield. European Journal of Agronomy 76, 1-16.
Couëdel A, Alletto L, Kirkegaard J \& Justes É (2018) Crucifer glucosinolate production in legume-crucifer cover crop mixtures. European Journal of Agronomy 96, 22-33.

Damour G, Dorel M, Quoc HT et al. (2014) A trait-based characterization of cover plants to assess their potential to provide a set of ecological services in banana cropping systems. European Journal of Agronomy 52, 218-228.

DeMendiburu F (2016) Statistical procedures for agricultural research. R Package Version 1.2.4. Available at: https://cra n.r-project.org/web/packages/agricolae/index.html (Last accessed 7 January 2016).

Díaz S, Lavorel S, de Bello F et al. (2007) Incorporating plant functional diversity effects in ecosystem service assessments. Proceedings of the National Academy of Sciences of the USA 104, 20684-20689.

Finn JA, Kirwan L, Connolly J et al. (2013) Ecosystem function enhanced by combining four functional types of plant species in intensively managed grassland mixtures: a 3-year continental-scale field experiment. Journal of Applied Ecology 50, 365-375.

FINNEY DM \& KAYE JP (2016) Functional diversity in cover crop polycultures increases multifunctionality of an agricultural system. Journal of Applied Ecology 54, 509517.

Finney DM, White CM \& Kaye JP (2016) Biomass production and carbon/nitrogen ratio influence ecosystem services from cover crop mixtures. Agronomy Journal 108, $39-52$.

Frasconi C, Antichi D, Fontanelli M et al. (2016) Techniques and machines for conservation and organic agriculture: the S.M.O.C.A. project. Journal of agricultural engineering 47, 3 .

Hauggaard-Nielsen H, Ambus P \& Jensen ES (2001) Interspecific competition, $\mathrm{N}$ use and interference with weeds in pea-barley intercropping. Field Crops Research 70, 101-109.

Hauggaard-Nielsen H, Mundus S \& Jensen ES (2009) Nitrogen dynamics following grain legumes and subsequent catch crops and the effects on succeeding cereal crops. Nutrient Cycling in Agroecosystems 84, 281-291.

Hooper DU, Chapin FS, Ewel JJ et al. (2005) Effects of biodiversity on ecosystem functioning: a consensus of current knowledge. Ecological Monographs 75, 3-35.

Hothorn T, Bretz F \& Westfall P (2008) Simultaneous inference in general parametric models. Biometrical Journal 50, 346-363.

Korsaeth A, Henriksen TM \& Bakken LR (2002) Temporal changes in mineralization and immobilization of $\mathrm{N}$ during degradation of plant material: implications for the plant $\mathrm{N}$ supply and nitrogen losses. Soil Biology and Biochemistry 34, 789-799.

Kruidhof HM, Bastianns L \& KropfF MJ (2008) Ecological weed management by cover cropping: effects on weed growth in autumn and weed establishment in spring. Weed Research 48, 492-502.

Kuo S \& SAINJu UM (1998) Nitrogen mineralization and availability of mixed leguminous and non-leguminous cover crop residues in soil. Biology and Fertility of Soils 26, 346-353.

Magagnoli S, Depalo L, Masetti A et al. (2017) Influence of agro-ecological service crop termination and synthetic 
biodegradable film covering on Aphis gossypii Glover (Rhynchota: Aphididae) infestation and natural enemy dynamics. Renewable Agriculture and Food Systems, 33, 386-392.

Malézieux E, Crozat Y, Dupraz C et al. (2009) Mixing plant species in cropping systems: concepts, tools and models. A review. Agronomy for Sustainable Development 29, 43-62.

Möller K, Stinner W \& Leithold G (2008) Growth, composition, biological N2 fixation and nutrient uptake of a leguminous cover crop mixture and the effect of their removal on field nitrogen balances and nitrate leaching risk. Nutrient Cycling in Agroecosystems 82, 233-249.

Moonen AC \& BÀrberi P (2004) Size and composition of the weed seedbank after 7 years of different cover-crop-maize management systems. Weed Research 44, 163-177.

MoOnen AC \& BÀrberi P (2008) Functional biodiversity: an agroecosystem approach. Agriculture, Ecosystems and Environment 127, 7-21.

Nakagawa S \& Schielzeth H (2013) A general and simple method for obtaining R2 from generalized linear mixedeffects models. Methods in Ecology and Evolution 4, 133142.

Njeru EM, Avio L, Sbrana C et al. (2014) First evidence for a major cover crop effect on arbuscular mycorrhizal fungi and organic maize growth. Agronomy for Sustainable Development 34, 841-848.

Petchey OL \& Gaston KJ (2006) Functional diversity: back to basics and looking forward. Ecology Letters 9, 741-758.

R Core Team (2017) R: A Language and Environment for Statistical Computing. R Foundation for Statistical Computing, Vienna, Austria. Available at: https://www.Rproject.org (Last accessed 7 January 2016).

Ramirez-Garcia J, Gabriel JL, Alonso-Ayuso M et al. (2015) Quantitative characterization of five cover crop species. The Journal of Agricultural Science 153, 1174-1185.

Ranaldo M, Costanzo A, Carlesi S \& Bàrberi P (2015) Can weed management in vegetable systems be improved by cover crop species mixtures? Step 1: Screening of cover crop species and varieties. In: Proceedings 2015 17th European Weed Research Society Symposium (ed. AFPP) (23-26 June 2015, Montpellier, France). 208. Alfortville, France.

RStudio Team (2016) RStudio: Integrated Development for R. RStudio, Inc., Boston, MA, USA. Available at: http:// www.rstudio.com
SChipAnSki ME, BARbercheck M, Douglas MR et al. (2014) A framework for evaluating ecosystem services provided by cover crops in agroecosystems. Agricultural Systems 125, 12-22.

Schmid B, Hector A, Saha P et al. (2008) Biodiversity effects and transgressive overyielding. Journal of Plant Ecology 1, 95-102.

Smith RG, Mortensen DA \& Ryan MR (2010) A new hypothesis for the functional role of diversity in mediating resource pools and weed-crop competition in agroecosystems. Weed Research 50, 37-48.

Smith RG, Atwood LW \& Warren ND (2014) Increased productivity of a cover crop mixture is not associated with enhanced agroecosystem services. PLOS ONE 9, e97351.

Sturm DJ, Peteinatos G \& Gerhards R (2018) Contribution of allelopathic effects to the overall weed suppression by different cover crops. Weed Research $\mathbf{5 8}$, 331-337.

Teasdale JR \& Abdul-Baki AA (1998) Comparison of mixtures vs. monocultures of cover crops for fresh-market tomato production with and without herbicide. HortScience 33, 1163-1166.

Tosti G, Benincasa P, Farneselli M et al. (2014) Barleyhairy vetch mixture as cover crop for green manuring and the mitigation of $\mathrm{N}$ leaching risk. European Journal of Agronomy 54, 34-39.

Triboulllois H, Fort F, Cruz P et al. (2015) A functional characterisation of a wide range of cover crop species: growth and nitrogen acquisition rates, leaf traits and ecological strategies. PLOS ONE 10, 1-17.

Wendling M, Büchi L, Amossé C et al. (2016) Influence of root and leaf traits on the uptake of nutrients in cover crops. Plant and Soil 409, 419-434.

Wiскнам H (2009) Ggplot2. Elegant Graphics for Data Analysis. Springer, New York, NY, USA.

Wortman SE, Francis CA \& Lindquist JL (2012) Cover crop mixtures for the western corn belt: opportunities for increased productivity and stability. Agronomy Journal 104, 699.

Wortman SE, Francis CA, Bernards MA et al. (2013) Mechanical termination of diverse cover crop mixtures for improved weed suppression in organic cropping systems. Weed Science 61, 162-170.

Zuur AF, Leno EN, Walker NJ et al. (2009) Mixed Effects Models and Extensions in Ecology with R. Public Health (ed. Springer Editor). Springer, New York, NY, USA. 